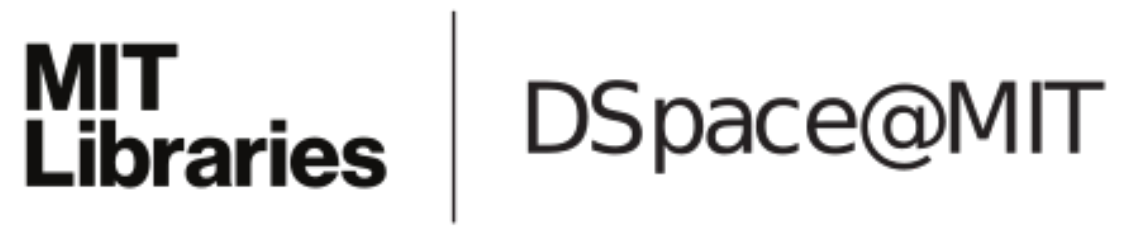

\author{
MIT Open Access Articles
}

\section{Potential Economic Value of Seasonal Hurricane Forecasts}

The MIT Faculty has made this article openly available. Please share how this access benefits you. Your story matters.

Citation: Emanuel, Kerry, Fabian Fondriest, and James Kossin. "Potential Economic Value of Seasonal Hurricane Forecasts." Weather, Climate, and Society 4.2 (2012): 110-117. (๐ 2012 American Meteorological Society

As Published: http://dx.doi.org/ 10.1175/wcas-d-11-00017.1

Publisher: American Meteorological Society

Persistent URL: http://hdl.handle.net/1721.1/75075

Version: Final published version: final published article, as it appeared in a journal, conference proceedings, or other formally published context

Terms of Use: Article is made available in accordance with the publisher's policy and may be subject to US copyright law. Please refer to the publisher's site for terms of use. 


\title{
Potential Economic Value of Seasonal Hurricane Forecasts
}

\author{
KERRY EMANUEL \\ Program in Atmospheres, Oceans, and Climate, Massachusetts Institute of Technology, Cambridge, Massachusetts \\ FABIAN FONDRIEST \\ Homesite Insurance, Boston, Massachusetts \\ JAMES KOSSIN \\ NOAA/National Climatic Data Center, Asheville, North Carolina, and Cooperative Institute for \\ Meteorological Satellite Studies, University of Wisconsin-Madison, Madison, Wisconsin
}

(Manuscript received 19 April 2011, in final form 22 January 2012)

\begin{abstract}
This paper explores the potential utility of seasonal Atlantic hurricane forecasts to a hypothetical property insurance firm whose insured properties are broadly distributed along the U.S. Gulf and East Coasts. Using a recently developed hurricane synthesizer driven by large-scale meteorological variables derived from global reanalysis datasets, 1000 artificial 100-yr time series are generated containing both active and inactive hurricane seasons. The hurricanes thus produced damage to the property insurer's portfolio of insured property, according to an aggregate wind-damage function. The potential value of seasonal hurricane forecasts is assessed by comparing the overall probability density of the company's profits from a control experiment, in which the insurer purchases the same reinsurance coverage each year, to various test strategies in which the amount of risk retained by the primary insurer, and the corresponding premium paid to the reinsurer, varies according to whether the season is active or quiet, holding the risk of ruin constant.

Under the highly idealized conditions of this experiment, there is a clear advantage to the hypothetical property insurance firm of using seasonal hurricane forecasts to adjust the amount of reinsurance it purchases each year. Under a strategy that optimizes the company's profits by holding the risk of ruin constant, the probability distribution of profit clearly separates from that of the control strategy after less than $10 \mathrm{yr}$ when the seasonal forecasts are perfect. But when a more realistic seasonal forecast skill is assumed, the potential value of forecasts becomes significant only after more than a decade.
\end{abstract}

\section{Motivation}

Several recent studies have demonstrated that as much as $65 \%$ of the year-to-year variance of Atlantic basin hurricane activity can be hindcast if the large-scale environmental conditions are well known (Knutson et al. 2007; Emanuel et al. 2008), even though synoptic-scale variability, such as African easterly waves, may not be known at all. This implies that if such large-scale conditions could be forecast many months in advance, some basinwide measures of hurricane activity might be predictable on such time scales. Even if one could forecast

Corresponding author address: Kerry Emanuel, MIT, 77 Massachusetts Ave., Rm 54-1814, Cambridge, MA 02139.

E-mail: emanuel@mit.edu such large-scale conditions perfectly, however, much of the tropical cyclone variance would not be predictable, owing to random chaotic influences, large-scale environmental factors not accounted for in the aforementioned modeling studies, or model error. Even if $65 \%$ of the variance of basinwide storm counts could be forecast perfectly, this would not necessarily translate into predictability of landfalling storms, which are almost always the events of interest, nor would it imply any predictability of the intensity of landfalling storms, which has a large effect on storm damage.

Here, we explore the potential economic value of seasonal hurricane forecasts. To provide an upper bound on the potential utility of such forecasts, we first examine the near-best-case scenario of perfect predictability of largescale conditions; later, we explore the effects of assuming 
more realistic forecast skill. We here focus on the economic utility of forecasts to a particular industry-the property insurance sector-under somewhat simplified but nevertheless realistic conditions. We regard the present study as developing a framework for estimating the potential economic value of seasonal hurricane forecasts rather than as a comprehensive estimate of such value across the entire economy.

\section{Methods}

Encouraged by the success of the aforementioned hindcasts of Atlantic basinwide hurricane activity, we explore the potential economic value to a property insurance firm of seasonal predictions of Atlantic hurricane activity. For the purposes of the present study, we aim for maximum simplicity and, in keeping with this philosophy, we assume that hurricane damage is the dominant source of volubility for insured losses; volubility owing to other sources would diminish the effects examined here. We also pretend that Atlantic hurricane seasons are divided into just two sets: active and quiet seasons. We represent quiet years by the large-scale conditions present during the hurricane season of 1991 , when just 7 named storms formed in the Atlantic region, and active years by the conditions present in 2003, which produced 16 named storms. We also assume that one can forecast with perfect accuracy and with about a 6-month lead time whether the coming season will be quiet or active. Using a synthetic hurricane generator to produce event sets appropriate to the quiet and active regimes, we create 1000 artificial time series of Atlantic hurricanes, each with a length of $100 \mathrm{yr}$ and involving both quiet and active years. Some of the hurricanes affect properties contained in a portfolio insured by a hypothetical insurance company, and a damage function is used to predict how much damage each storm will do to these properties. Thus, we generate 1000 nearly independent possible realizations of 100-yr time series of damage to the portfolio. We use these time series to compare different possible strategies that a property insurance firm might take. In a control strategy, the firm takes out identical excess-of-loss reinsurance contracts each year, paying a premium to the reinsurer, who then covers all losses for each individual event in excess of an agreed upon amount; the primary insurer retains all losses below this amount. This strategy is then compared to an optimal strategy in which the primary insurer negotiates different retentions in different years (and with correspondingly different annual premiums) according to whether the upcoming season will be active or quiet. The relative success of this strategy is measured by probability distributions of the company's profits under the constraint that its probability of ruin remains constant. The sections below describe our methods in detail.

\section{a. Hurricane event sets}

The historical record of Atlantic hurricanes is too short and contains too few events to develop a statistically robust estimate of hurricane damage to the U.S. East Coast. For this reason, we use a synthetic hurricane generator developed by Emanuel et al. (2008). This method begins with a global dataset of key meteorological variables, including wind at two altitudes in the atmosphere, sea surface temperature, and temperature and humidity through the whole troposphere and lower stratosphere. This global dataset may be produced by global models; but in the present case, we use data from analyses of the atmosphere produced by the National Centers for Environmental Prediction (Kalnay et al. 1996). In the first step, the given climate state is seeded, randomly in space and time, with weak proto-hurricanes. Once seeded, the nascent storms are assumed to move with the large-scale winds of the given climate state, with a small correction owing to the earth's rotation. Finally, their intensity is predicted using a detailed, coupled ocean-atmosphere hurricane model, again driven by the large-scale climate variables. In general this model predicts that most of the proto-hurricanes fail to develop; these failed events are discarded. The small fraction of proto-hurricanes that develop then constitute the hurricane climatology according to this method. Details may be found in Emanuel et al. (2008).

When applied to the quiet Atlantic hurricane season of 1991, this method predicts that 7.5 named storms should have developed versus the observed 7 named storms, while it predicts 15.5 named storms in 2003, which in fact produced 16 storms (the fractional annual storm count results from having produced 10000 synthetic events for each year and comparing this number to the number of seeded storms that failed to develop). This and evidence presented in Emanuel et al. (2008) suggests that the method is capable of distinguishing active from quiet years.

Using these two synthetic datasets, we create artificial 100-yr time series of Atlantic hurricanes. To do this, we first create a single 100 -yr series of randomly ordered ones and zeros representing active and quiet years. We generate a storm count for each year by drawing randomly from a Poisson distribution based on the long-term mean frequency of events, using the long-term mean frequency as appropriate from the active or quiet dataset. We then randomly select that number of events from the quiet or active 10000 -member event set as appropriate. Because climatic conditions (such as El Niño) often exhibit "memory" from one year to the next, here we 
choose whether a year is quiet or active from an autoregressive series that exhibits some memory from year to year but insures that there are exactly 50 members each of active and quiet seasons. We create 1000 such 100-yr series, differing only in the particular random draws from the Poisson distribution in each year. By this means, we create one thousand $100-y r$ time series of hurricane events containing an autoregressive sequence of equal numbers of active and quiet years.

\section{b. Hurricane vulnerability}

Estimating the damage that a particular hurricane causes requires detailed estimates of the value of each property affected by the storm as well as the vulnerability of that property to storm-related effects, such as wind and storm surge. For the purposes of the present work, we greatly simplify this calculation to include only wind damage, and we assume that a given history of wind reduces the value of all properties by the same fraction, neglecting variations in vulnerability from one property to the next.

We begin with a database of insured property values, the Industry Exposure Database, produced by Risk Management Solutions Inc. (A. Lange 2010, personal communication). This consists of estimates of total insured values for each zip code and county in the United States and for each postcode in Europe, using sampled company premium information, census demographics and economics data, building square footage data, and representative policy terms and conditions. These total insured values and other variables are then aggregated into 100 zones distributed along the U.S. Gulf and East Coasts, as shown in Fig. 1. The latitudes and longitudes represent roughly the geographical centers of the zones. Again, for simplicity, we model the damage in a given zone according to the wind experienced at the position of the zone center. For the smaller zones, this may be a good approximation; but for the larger zones, it yields only a rough estimate. For each hurricane event, we use a wind-damage function (described in the next subsection) to estimate the fractional loss of value in each zone and multiply this by the total insured value of property in that zone. This gives an estimate of the total amount of damage in U.S dollars caused by each event in each zone; the total insured damage from an event is then the sum of this quantity over all zones. We assume that our hypothetical company's share of the property value and damage is a fixed fraction of those of the entire insured property portfolio. This assumption will overestimate damages for insurance companies whose insured properties are weighted away from hurricane-prone regions and underestimate it for companies more heavily invested in hurricane regions.

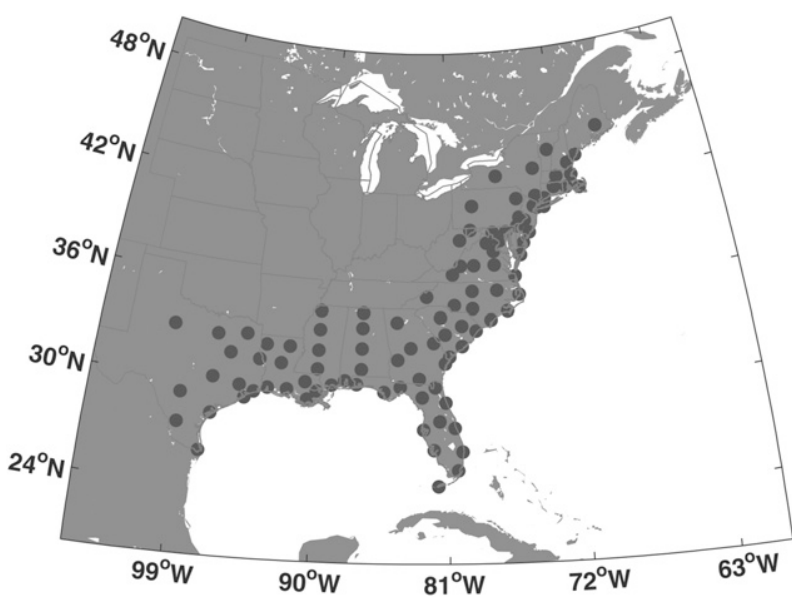

FIG. 1. Centers of zones (black dots) used to estimate property damage caused by tropical cyclones.

\section{c. Wind-damage function}

Property damage from wind storms is observed to increase quite rapidly with wind speed. On theoretical grounds, one might expect damage to scale as the cube of the wind speed, which is proportional to the total power dissipated frictionally when wind blows over a rough surface. But empirical studies relating wind to damage suggest much higher power-law dependencies of damage on wind (Pielke 2007). For example, Nordhaus (2010) estimates that damage varies as the ninth power of wind speed for wind damage in the United States. In reality, most structures in the United Stsates are built to withstand frequently encountered winds; it is highly unlikely, for example, that a wind of $20 \mathrm{kt}$ would do any damage at all. Thus, we consider a damage function that produces positive values only for wind speeds in excess of a specified threshold (Emanuel 2011). On physical grounds, we expect that damage should vary as the cube of the wind speed over a threshold value. Finally, we require that the fraction of the property damaged approach unity at very high wind speeds and, in any event, we cannot allow it to exceed unity. A plausible function that meets these requirements is

$$
f=\frac{v_{n}^{3}}{1+v_{n}^{3}}
$$

where $f$ is the fraction of the property value lost and

$$
v_{n} \equiv \frac{\operatorname{MAX}[(V-50 \mathrm{kts}), 0]}{60 \mathrm{kts}},
$$

with $V$ as the wind speed in knots. This function is plotted in Fig. 2. Half the property value is lost when the 


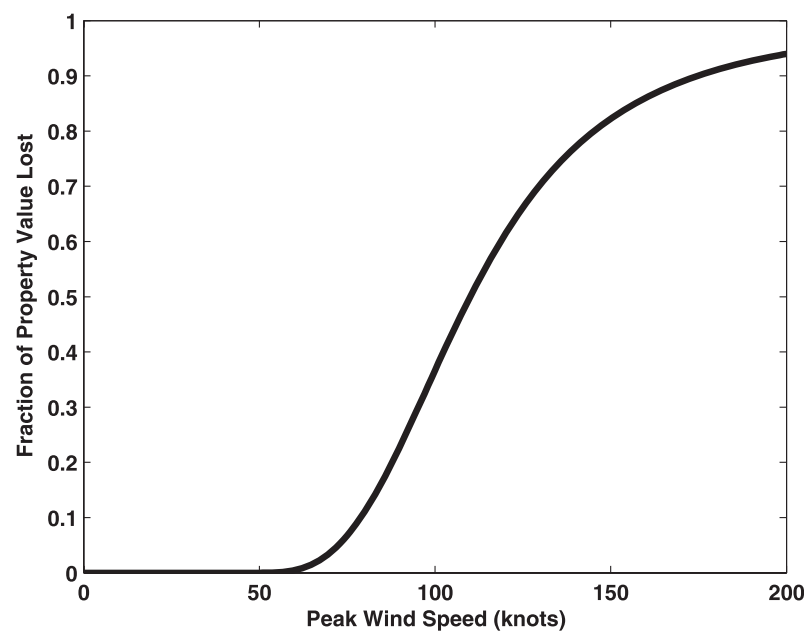

FIG. 2. Fraction of property value lost as a function of wind speed using Eq. (1)

wind speed reaches $110 \mathrm{kt}$. In reality, property damage depends on much more than the peak wind speed experienced during a storm; for example, the direction of the wind, its degree of gustiness, and the duration of damaging winds all influence the amount of damage. But again in the spirit of simplicity, we estimate aggregate damage in each zone by the peak 1-min wind speed at $10 \mathrm{~m}$ altitude experienced at the geographical center of the zone during the course of each event. For the purposes of this exercise, we do not consider variability from one region to the next in the susceptibility of structures to wind, assuming that the same wind will do the same fractional damage no matter where it occurs. While not realistic, we do not expect such variability to have any significant influence on the main findings of the present work, which compares damage done in quiet and active years.

\section{d. Hypothetical property insurance business}

Our hypothetical primary insurance business begins with a fixed amount of capital. To keep things simple, we assume that the only losses experienced by the company are those owing to hurricanes, and that there is a constant revenue stream that, over the $100-\mathrm{yr}$ period and averaged over the 1000-member ensemble, is such that the company neither gains nor loses value. (In reality, an insurance company would insure against losses other than hurricanes, such as fire, but we assume that these are random, small events that do not contribute appreciably to the volatility of the company's business; we essentially assume that there is a separate revenue stream that balances these losses together with operating expenses. The presence of any nonhurricane sources of volubility would dilute the value of seasonal hurricane forecasts that we examine here.) Any investment income is included in our definition of the annual revenue. We do not include the effects of inflation.

If the company's net capital were to increase with time, owing, for example, to its use of seasonal hurricane forecasts, then it could use the increased capital in many different ways. For example, it could be used to reduce its reinsurance coverage, retaining greater potential losses that it can cover with its increased capital. But here, for simplicity, we assume that if, at the end of each year, the company's capital has increased above its starting capital, then the excess capital is distributed as dividends to its shareholders.

Owing to the comparatively rare instance of intense hurricanes at a given location, there will be a degree of volatility of the company's value. A few large losses in a row, for example, will decrease the company's net worth by a substantial margin, whereas a period of relative inactivity will lead to an increase in net worth. We will suppose here that if the net worth drops below $30 \%$ of its initial capital, the company will go out of business. We regard this number as a lower bound, in keeping with our strategy of erring on the side of high potential utility of seasonal forecasts; in reality, marketplace and regulatory pressures would likely force the insurer out of business ${ }^{1}$ at levels somewhat higher than this. To decrease such volatility, real companies purchase reinsurance policies, which can take any of a large number of forms. Here, we will simply suppose that the primary insurer takes out excess-of-loss reinsurance that reimburses all losses over a specified cap in a given year; the primary insurer retains all losses below the specified cap. ${ }^{2}$ The primary insurer loses revenue by having to pay a premium to its reinsurer but gains when the latter covers losses in excess of the cap. We begin by designing a base premium such that, over the 1000-member ensemble of 100-yr integrations, the net worth of the primary insurer remains constant over all retentions in a scenario in which the reinsurance contract (including the premium) is the same every year. This base premium should be thought of as what the reinsurer would need to charge, for each retention, to break even, assuming no costs other than hurricane losses. In reality, the reinsurer must cover a variety of other costs, including especially the costs of dealing with the volatility of hurricane losses. To account for this while adhering to the spirit of simplicity, we assume here that the reinsurer's premium is twice the base premium. Figure 3 shows the annual

\footnotetext{
${ }^{1}$ Notwithstanding that capital infusions from a parent company or a buyout may save the company.

${ }^{2}$ Most such policies also place a cap on the total amount that is covered by a single event. For simplicity, we place no such cap here.
} 


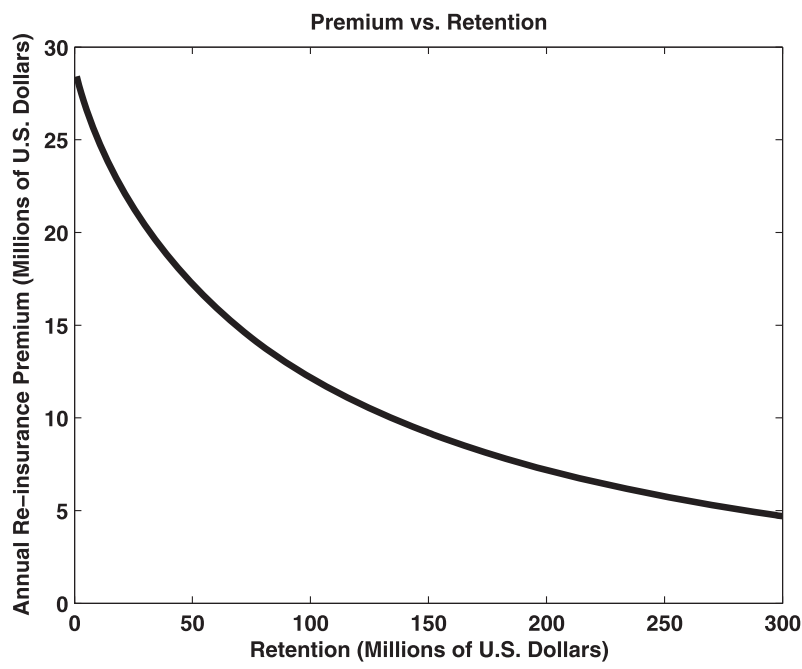

FIG. 3. Annual premium vs annual retention.

premium paid to the reinsurer as a function of the amount of risk retained by the primary insurer, while Fig. 4 shows how the probability of ruin over $100 \mathrm{yr}$ varies with the premium paid by the primary insurer, assuming that the primary insurer's initial capital is $\$ 250$ million. By design, the primary insurer will choose an annual retention that optimizes its annual revenues against the probability of ruin. Here, we assume that the optimum point corresponds to a risk of ruin over $100 \mathrm{yr}$ of $12 \%$, or roughly $0.1 \%$ each year. By "ruin," we specifically mean an outcome that is unacceptable to shareholders and/or regulators and would likely result in at least a major reorganization, if not an outright shuttering of the firm. Lowering the risk of ruin would entail a more conservative strategy (e.g., ceding more risk to a reinsurer) that would result in lower short-term profits, while increasing it would increase profitability but risk lowering the firm's rating.

\section{e. Baseline operating strategy}

We run a 1000-member ensemble of 100-yr time series of Atlantic hurricanes and tally the losses and gains to the primary insurer for each ensemble member resulting from hurricane impacts on each of the 100 zones shown in Fig. 1, using the fractional damage function given by Eq. (1). In tallying the variables that control the primary insurer's performance, there are a few essential nondimensional parameters. The first is the ratio of the initial capital to the mean or median of the annual losses, which measures the degree to which the company is at risk in the absence of reinsurance. Another important number is the ratio of the risk retained by the company (the cap described above) to its initial capital. Mindful of these important nondimensional numbers, we nevertheless

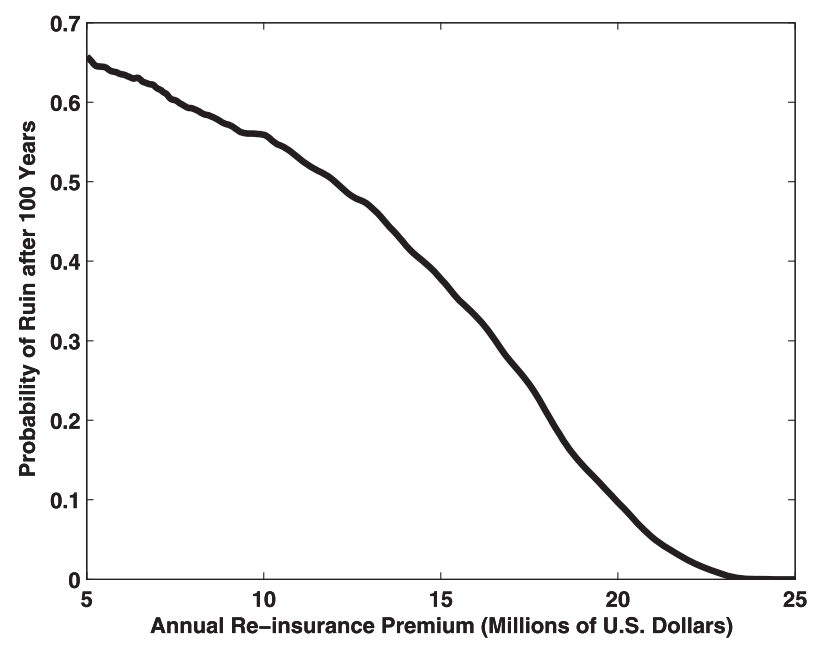

FIG. 4. Probability of ruin after $100 \mathrm{yr}$ as a function of annual premium.

present the results in dollar amounts for illustrative purposes. In particular, our hypothetical company is taken to begin with $\$ 250$ million in capital. Note that the shape of the curve shown in Fig. 4 depends crucially on the ratio of the initial capital to the median annual loss.

For the baseline scenario, we have the company retain $\$ 30$ million in losses for each hurricane event, for which it pays its reinsurer an annual premium of $\$ 20,363,000$ so as to maintain the $100-\mathrm{yr}$ probability of ruin at $12 \%$. At the end of every year, the amount of capital (if any) in excess of the starting capital of $\$ 250$ million is paid out as dividends to shareholders, resetting the capital to $\$ 250$ million. No capital is added to the company if its yearend capital is less than $\$ 250$ million. In this control experiment, the capital remaining after $100 \mathrm{yr}$, averaging over the 1000-member ensemble, is $\$ 194$ million, while the ensemble-average dividend payout, accumulated over $100 \mathrm{yr}$, is $\$ 59$ million. Although we have chosen to assume that all the profitability of the hypothetical insurance firm accrues to shareholders for the purposes of this paper, in reality some fraction of any increase in profitability (e.g., from utilizing seasonal hurricane forecasts) would be used to reduce premiums, thereby benefitting ratepayers as well as shareholders (Kunreuther et al. 1995).

\section{f. Using seasonal forecasts}

Owing to state-imposed regulation, primary insurers in the United States have relatively few degrees of freedom they can exercise from one year to the next. For example, most states have regulations preventing primary insurers from cancelling policies without just cause, so that insurers can only choose locations to insure when writing new policies. Similarly, rates are strongly regulated, so that insurers must ask state commissioners to 
approve rate increases, and this, to the extent that it happens at all, requires substantial lead time. Insurers can elect not to renew policies when they are up for renewal, but even this is regulated in some states. Even if interannual climate variability had predictable spatial patterns, it is unlikely that insurers would systematically attempt to shift the geographic distributions of its policies on an annual time scale.

One degree of freedom that insurers can exercise on an annual basis is the choice of how much loss they are prepared to retain in reinsurance contracts. They can, for example, choose to retain more loss in a year when they expect losses to be smaller. In practice, this degree of freedom may also be limited by regulation and by the need for the company to maintain a sufficiently high rating. But here we will simply assume that the company has complete freedom in choosing its retention from one year to the next.

One strategy for making use of a seasonal forecast is to retain a smaller loss cap in years when a high level of hurricane activity is expected, and a higher loss cap in years when smaller activity is predicted. We shall assume for the time being that the reinsurer maintains a constant pricing scheme of premium as a function of retention, regardless of the seasonal hurricane forecast, thus we give all the potential value of seasonal forecasts to the primary insurer. (Future work will apply game theory to the interaction between the primary insurer and the reinsurer.)

To optimize the value of the seasonal forecasts, we adjust the quiet and active season retentions so as to maximize the profit accumulated over $100 \mathrm{yr}$, averaged over the 1000 -member ensemble, subject to the condition that the $100-\mathrm{yr}$ risk of ruin always remains at $12 \%$, as in the control strategy. It transpires that the net profit as a function of quiet- and active-year retentions has a broad peak over a range of retention pairs, but the absolute peak is achieved for a quiet-year retention of $\$ 119$ million and an active-year retention of only $\$ 18$ million. For this combination, the capital remaining after $100 \mathrm{yr}$, averaging over the 1000-member ensemble, is \$229 million, and the ensemble-average dividend payout, accumulated over $100 \mathrm{yr}$, is $\$ 340$ million.

\section{Results}

Figure 5 shows the time history of the net worth of the company for 10 of the 1000 realizations, in the control experiment in which the company retains $\$ 30$ million in potential losses for each event each year. (For this retention, the probability of going out of business before $100 \mathrm{yr}$ is $12 \%$.) The net value resembles a random walk but with an asymmetry of slow gains because of a steady

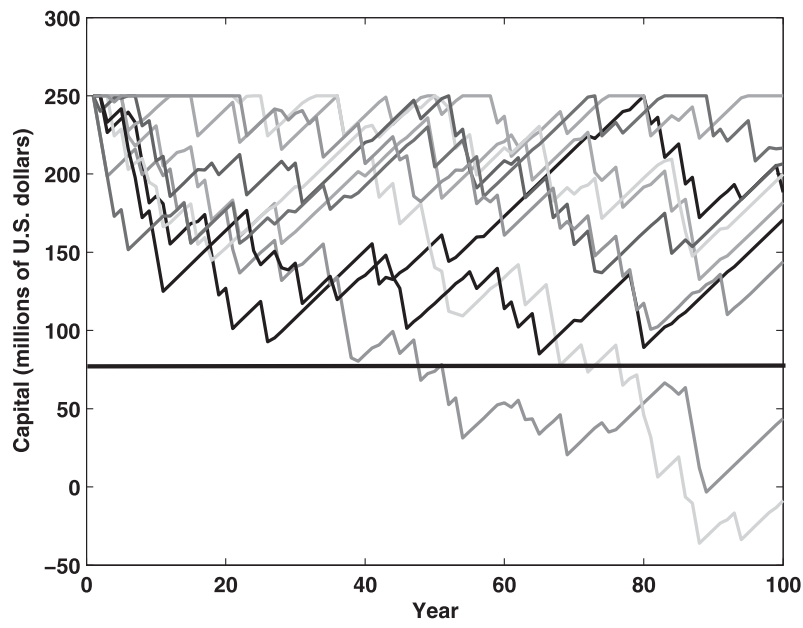

FIG. 5. Ten realizations of the net worth of the primary insurer over $100 \mathrm{yr}$, given an annual retention of $\$ 30$ million and a starting capital of $\$ 250$ million. Thick horizontal line represents the minimum capital for the company to stay in business. Two of these 10 realizations fail before $100 \mathrm{yr}$.

revenue stream punctuated by large losses owing to rare hurricane events. Clearly, two of the realizations show the company going out of business before $100 \mathrm{yr}$. At the opposite extreme, a few realizations are hardly affected by storms over the entire 100 -yr period. Recall that when the capital exceeds $\$ 250$ million, the excess is distributed to shareholders and the company's capital is reset to $\$ 250$ million.

Figure 6 shows the probability density of the company's net worth after $10,20,50$, and $100 \mathrm{yr}$ for the control strategy, using all 1000 realizations, and compares it to the strategy that optimally uses hypothetically perfect seasonal forecasts of whether the large-scale conditions favor an active or a quiet season. In this optimal strategy, the risk retained by the primary insurer is reduced to $\$ 18$ million in active seasons and increased to $\$ 119$ million in quiet seasons, with the premium paid to the reinsurer adjusted accordingly. Clearly, the optimal strategy greatly increases the dividends paid to shareholders while holding constant the risk of ruin, and the difference is clearly discernable even after only $10 \mathrm{yr}$.

To examine the effect of forecast imperfection, we assume that a randomly selected 40 of the 100 forecasts are wrong (e.g., an active year is forecast and a quiet year ensues). Note that 50 wrong forecasts corresponds to zero forecast skill in this case; assuming that 40 forecasts are wrong is broadly consistent with the current marginal skill seen in seasonal hurricane forecasts in the Atlantic region (Owens and Landsea 2003). We reoptimize the primary insurer's retention strategy so as to hold constant the $100-y r$ risk of ruin . The optimum strategy in this case retains $\$ 50$ million in quiet 


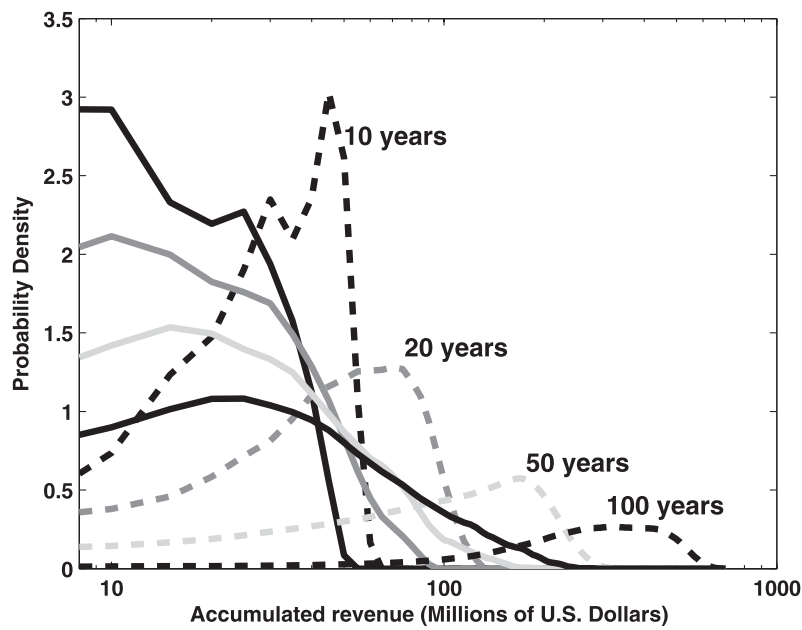

FIG. 6. Probability density of accumulated revenue after 10, 20, 50, and $100 \mathrm{yr}$, based on 1000 realizations, for the control strategy (solid) that retains $\$ 30$ million in losses each year and the optimal strategy for using seasonal forecasts (dashed) that increase retention to $\$ 119$ million in quiet years and decrease it to $\$ 18$ million in active years. Shades of gray correspond to accumulated dividend periods as labeled in years. Note that the abscissa is plotted on a log scale.

years and $\$ 28$ million in active years - a much smaller spread than the optimum strategy yields when forecasts are perfect. For this combination, the capital remaining after $100 \mathrm{yr}$, averaging over the 1000-member ensemble, is $\$ 212$ million, and the ensemble-average dividend payout, accumulated over $100 \mathrm{yr}$, is $\$ 113$ million. The probability distribution of revenue after $50 \mathrm{yr}$ is shown in Fig. 7 and compared to the control and perfect forecast results. The effect of forecast imperfection is clearly evident, with the probability distribution of accumulated revenue using flawed forecasts much closer to the control strategy distribution than to the distribution when the strategy is optimized to take advantage of perfect forecasts.

\section{Discussion}

In approaching the problem of the potential utility of seasonal hurricane forecasts, we have deliberately erred on the side of maximum potential utility. We have chosen an artificially large climate signal-the difference between one very active and one very inactive Atlantic hurricane season-and we have assumed that the largescale climate, insofar as it affects hurricanes, has some degree of predictability at the time a reinsurance contract is negotiated (usually the prior winter).

Owing to the large cost of reinsurance, reflecting the high cost of dealing with the large volatility of hurricane losses, primary insurers can potentially save a great deal of reinsurance premium in quiet years while being able

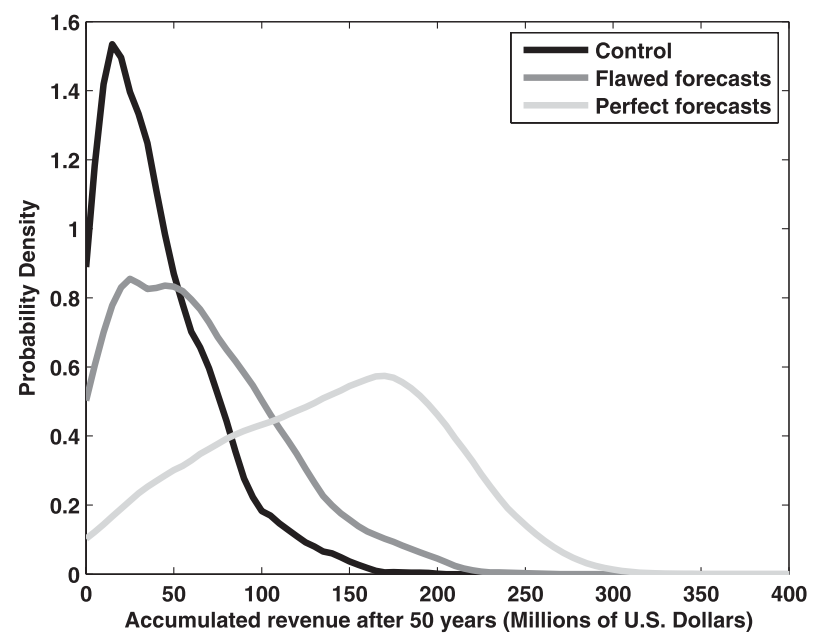

FIG. 7. Probability density of accumulated revenue after $50 \mathrm{yr}$ when $40 \%$ of the forecasts are wrong (dark gray) compared to the control strategy (black) and the optimal strategy when the forecasts are perfect (light gray). For the flawed forecasts, $\$ 50$ million in losses are retained by the primary insurer when the forecast is for a quiet year, while $\$ 28$ million are retained when the forecast is for an active year. Note that in this case, the abscissa is linear in accumulated revenue.

to afford more protection in active years. The net savings are large enough that, in the framework of a 1000-member ensemble, there is a high probability of realizing gains from perfect seasonal forecasts after only $10 \mathrm{yr}$ or so, provided perfect forecasts are available. Of course, in reality, reinsurers would quickly adjust their premium rates to take advantage of such seasonal forecasts, whose benefits would consequently become shared between the primary insurer and the reinsurer. Moreover, there are other options available to primary insurers, including tiered pricing schemes in which the premium paid is a function not only of retention but varies with the "layers" of risk in excess of the retention. Current seasonal forecasts have only marginal skill (Owens and Landsea 2003), and when this is accounted for, there is correspondingly less potential benefit from the forecasts.

The overall results are summarized in Table 1, which shows the ensemble mean revenue at various times for each of the three experimental conditions examined. Perfect forecasts have potential value to the primary insurer even after a short time, while the value of more realistically flawed forecasts only becomes evident after somewhat more than a decade.

\section{Summary}

We here explored the potential economic value to a hypothetical property insurance firm of seasonal 
TABLE 1. Ensemble mean revenue (in millions of dollars) after the indicated number of years for the control, flawed forecast, and perfect forecast experiments. In each case, the 100 -yr probability of ruin is held at $12 \%$.

\begin{tabular}{lcccr}
\hline \hline $\begin{array}{c}\text { Experimental } \\
\text { conditions }\end{array}$ & $\begin{array}{c}10-\mathrm{yr} \\
\text { revenue }\end{array}$ & $\begin{array}{c}20-\mathrm{yr} \\
\text { revenue }\end{array}$ & $\begin{array}{c}50-\mathrm{yr} \\
\text { revenue }\end{array}$ & $\begin{array}{r}100-\mathrm{yr} \\
\text { revenue }\end{array}$ \\
\hline Control & 18.2 & 25.9 & 39.2 & 59.3 \\
$40 \%$ wrong forecasts & 19.4 & 37.2 & 63.1 & 113.1 \\
Perfect forecasts & 33.9 & 59.1 & 136.2 & 340.1 \\
\hline
\end{tabular}

predictions of Atlantic hurricane activity. Aiming for maximum simplicity, we pretended that Atlantic hurricane seasons are divided into just two sets: active and quiet seasons. We represented quiet years by the largescale conditions present during the inactive hurricane season of 1991 and active years by the conditions present in 2003. We also assumed that the primary insurer had, at the time it negotiated reinsurance contracts, access to forecasts of whether the coming season will be active or quiet. We used a synthetic hurricane generator to produce event sets appropriate to the quiet and active regimes and created 1000 artificial time series of Atlantic hurricanes, each with a length of $100 \mathrm{yr}$ and involving both quiet and active years. Some of the hurricanes affected properties contained in a portfolio insured by a hypothetical insurance company, and a damage function was used to predict how much damage each storm would do to these properties. We used the resulting time series of hurricane damage to compare different possible strategies that the hypothetical primary insurer might take. In the control strategy, the firm takes out identical excess-of-loss reinsurance contracts each year. This strategy was compared to an optimal strategy in which the primary insurer negotiates different retentions in different years (and with correspondingly different annual premiums) according to whether the upcoming season will be active or quiet, maintaining a constant level of overall risk to the company. In one case, we assumed perfect forecasts and in another, more realistic scenario, we assumed only marginally skillful seasonal forecasts. The relative success of this strategy was measured by probability distributions of the company's net profit.

When the seasonal forecasts are perfect, there is a clear advantage to using them to adjust the amount of risk retained by the primary insurer, with the advantage becoming apparent after only about $10 \mathrm{yr}$. Thus, perfect seasonal forecasts would have a decided utility in the property insurance sector under the idealized conditions assumed here. It is less clear whether the insurance sector can make profitable use of seasonal forecasts that are far from perfect, as is currently the case. Taken together, these results suggest that improved seasonal forecasts of Atlantic hurricane activity could greatly increase their economic value, at least to the insurance industry.

Although we use profitability as a simple measure of forecast influence here, in reality market forces would at least partially substitute lower premiums for increased profits, and reinsurers would respond to fluctuating demand by adjusting their pricing accordingly. These effects will be the subject of future work on this problem.

Acknowledgments. The authors thank Risk Management Solutions, Inc. for making available its proprietary Industry Exposure Database and Alan Lange for processing these data. We are grateful for helpful advice from Rick Murnane, Jan Klein, and two anonymous reviewers. The first author's research was supported by the National Oceanic and Atmospheric Administration under Grant NA090AR4310131.

\section{REFERENCES}

Emanuel, K., 2011: Global warming effects on U.S. hurricane damage. Wea. Climate Soc., 3, 261-268.

, R. Sundararajan, and J. Williams, 2008: Hurricanes and global warming: Results from downscaling IPCC AR4 simulations. Bull. Amer. Meteor. Soc., 89, 347-367.

Kalnay, E., and Coauthors, 1996: The NCEP/NCAR 40-Year Reanalysis Project. Bull. Amer. Meteor. Soc., 77, 437-471.

Knutson, T. R., J. J. Sirutis, S. T. Garner, I. M. Held, and R. E. Tuleya, 2007: Simulation of the recent multidecadal increase of Atlantic hurricane activity using an 18-km-grid regional model. Bull. Amer. Meteor. Soc., 88, 1549-1565.

Kunreuther, H., J. Meszarous, R. Hogarth, and M. Spranca, 1995: Ambiguity and underwriter decision processes. J. Econ. Behav. Organ., 26, 337-352.

Nordhaus, W. D., 2010: The economics of hurricanes and implications of global warming. Climate Change Econ., 1, 1-20.

Owens, B. F., and C. W. Landsea, 2003: Assessing the skill of operational Atlantic seasonal tropical cyclone forecasts. Wea. Forecasting, 18, 45-54.

Pielke, R. A., Jr., 2007: Future economic damage from tropical cyclones: Sensitivities to societal and climate changes. Philos. Trans. Roy. Soc. London, A365, 1-13. 